\title{
Perfluorohexane-encapsulated fullerene
} nanospheres for dual-modality US/CT imaging and synergistic high-intensity focused ultrasound ablation

\author{
Kunyan $\mathrm{He}^{1}$ \\ Haitao Ran ${ }^{2,3}$ \\ Zhongzhen Su' \\ Zhigang Wang ${ }^{2,3}$ \\ Maoping $\mathrm{Li}^{4}$ \\ Lan $\mathrm{Hao}^{3}$
}

'Ultrasound Department, The Fifth Affiliated Hospital, Sun Yat-sen University, Zhuhai, Guangdong Province 519000, People's Republic of China; ${ }^{2}$ Ultrasound Department, The second Affiliated Hospital, Chongqing Medical University, Chongqing 4000I0, People's Republic of China; ${ }^{3}$ The Institute of Ultrasound Imaging, Chongqing Medical University, Chongqing 4000I0, People's Republic of China; ${ }^{4}$ Ultrasound Department, The First Affiliated Hospital, Chongqing Medical University, Chongqing 4000I0, People's Republic of China
This article was published in the following Dove Medical Press journal:

International Journal of Nanomedicine

\begin{abstract}
Purpose: The objective of this study was to develop a multifunctional contrast agent for bioimaging and synergistic high-intensity focused ultrasound (HIFU) therapy to achieve theranostic.

Materials and methods: A novel type of perfluorohexane-encapsulated fullerene ( $\left.\mathrm{PFH}-\mathrm{C}_{60}\right)$ nanosphere was successfully developed via a vacuum ultrasonic emulsification and centrifugation method and subsequently used in ultrasound/computed tomography (CT) dual-modality and HIFU ablation of dissected bovine livers. In addition, transmission electron microscopic examination was employed to detect structural changes in the target tissue for HIFU ablation. Results: The use of composite nanospheres effectively enhanced ultrasound and CT imaging. Moreover, the HIFU ablation of dissected bovine livers was also significantly enhanced.

Conclusion: Composite nanospheres demonstrate potential theranostic application as a multifunctional contrast agent for dual-modality biological imaging and highly efficient synergistic imaging-guided HIFU ablation.
\end{abstract}

Keywords: microbubble, noninvasive therapy, double modal imaging, sonodynamic effects, synergistic ablation efficiency

\section{Introduction}

Within recent years, local thermal ablation of tumors has become an important treatment method, in comparison with methods that employ radiation high-intensity focused ultrasound (HIFU) is a novel noninvasive, local tumor ablation technique that has undergone rapid development over the past few years. ${ }^{1-4}$ Lynn et al originally proposed HIFU in the 1940s while performing neurologic surgery. ${ }^{5}$ The HIFU technique utilizes high-energy-focusing devices, which focus external ultrasound energy on tumor tissues in vivo and generate high temperatures at the focal point, and thereby exert thermal effects, cavitation effects, and mechanical action, resulting in protein denaturation and irreversible coagulation necrosis of tumor tissues, which then become gradually absorbed or form scars. ${ }^{6,7}$ The HIFU technique has been successfully applied in the treatment of a variety of benign and malignant solid tumors. ${ }^{6}$ Compared to other treatment modalities (radiation therapy, chemotherapy, etc), HIFU permits noninvasive, real-time monitoring before, during, and after the therapeutic process. ${ }^{8}$ However, ultrasonic waves tend to undergo energy decay when propagated in tissues, particularly deep tissues, thereby affecting the therapeutic effects of HIFU. ${ }^{9-11}$ High ultrasound power is absolutely necessary to achieve favorable therapeutic outcomes. Such high 
power ultrasound energy could also lead to the destruction of normal tissue in the path of ultrasound transmission, leading to serious side effects such as nerve damage, skin burns, and transient pain. ${ }^{12-14}$ Thus, particularly for HIFU therapy, high therapeutic efficiency with low energy is required.

Microbubbles have been widely recognized for their strong enhancement effects, and they can improve the efficacy of HIFU via enhanced thermal and cavitation effects. ${ }^{15-17}$ However, microbubbles have relatively large diameters. As a result, the occurrence and scope of cavitation are both uncontrollable and may result in displacement of the treatment area, thus damaging normal tissue. Therefore, the clinical application of microbubbles as HIFU enhancement agents is limited. ${ }^{18}$ In light of this, we proposed a nanoscale substance that would be directly introduced in the vicinity of target cells and produce bubbles under the effect of HIFU. This substance could exert enhancement effects similar to those of microbubbles. Several studies have reported that the introduction of HIFU enhancement agents, such as the perfluorohexane (PFH)-encapsulated nanocapsules, can increase energy deposition in target tissues and thus significantly enhance the therapeutic efficiency of HIFU. ${ }^{8,19}$ As a member of the large liquid fluorocarbon family of compounds, $\mathrm{PFH}$ has a boiling point of $58^{\circ} \mathrm{C}-60^{\circ} \mathrm{C} .{ }^{20}$ Liquid fluorocarbons can transition from the liquid state to the gaseous state after being triggered by ultrasound stimulation or heating. In addition, ultrasound stimulation is considered the most effective means to promote acoustic droplet vaporization (ADV). ${ }^{18,21}$

Over the span of 33 years, fullerenes $\left(\mathrm{C}_{60}\right)$ have attracted the attention of scientists because of their unique chemical and physical properties. Functionalized fullerenes have been investigated for biomedical applications, such as radiation protection, drug delivery, magnetic resonance imaging contrast agents, photodynamic therapy, and gene therapy. Under specific conditions, fullerenes have the unique ability to generate reactive oxygen species (ROS) and killer cells. Depending on their functionalization, fullerenes can effectively inactivate malignant cancer cells and pathogenic microbial cells. ${ }^{22,23}$ In light of these findings, in this study, we synthesized a new material composed of nanospheres as a HIFU enhancement agent based on a liquid perfluorocarbon (ie, PFH) and fullerene. We also conducted a preliminary investigation of its use with computed tomography (CT) and ultrasound imaging technologies and examined its HIFU enhancement effects via in vitro experiments. We integrated CT and ultrasonography for two main reasons. First, CT and ultrasonography are both diagnostic modalities that are generally applied in clinical and various experimental settings. Second, ultrasonography is widely used as a realtime imaging measure to guide HIFU therapy; however, its images can be affected by several factors, such as air in the lung, bones, and intestinal gas. On the other hand, CT is not adversely affected by these factors. The integration of CT and ultrasonography should provide more comprehensive information to facilitate accurate imaging guidance and diagnosis.

\section{Materials and methods Preparation of liquid PFH nanospheres}

The materials used hydroxy fullerene powder (polyhydroxy$\mathrm{C}_{60}$; Suzhou Dade Carbon Nanotechnology Co., Ltd, People's Republic of China), 25\% ethanol, and liquid PFH (formula: $\mathrm{F}_{14} \mathrm{C}_{6}$, with a boiling point of $\left.58^{\circ} \mathrm{C}-60^{\circ} \mathrm{C}\right)$. The main equipment used an electronic balance (FA1004N; Shanghai, People's Republic of China), ultrasonic wave processor (VCY-500C; Shanghai, People's Republic of China), and a high-speed centrifuge (TG18; Pingfan Instrument and Meter Co., Ltd, Changsha, People's Republic of China).

Vacuum ultrasonic emulsification and centrifugation methods were used. Hydroxy-modified fullerene $(50 \mu \mathrm{g})$ was dissolved in $10 \mathrm{~mL}$ of $25 \%$ ethanol and placed into a sealed tube. After vacuuming, $4 \mathrm{~mL}$ of liquid $\mathrm{PFH}$ was injected to the solution, following which ultrasonication was applied at $50 \mathrm{~W}$ for 40 seconds to obtain an aggregation-free suspension. The suspension was sealed and stored under refrigeration for 12-24 hours. The suspension was then centrifuged at 10,000 rpm for 5 minutes and subjected to three cycles of washing with double-distilled water, followed by centrifugation and collection. Subsequently, black-brown solid nanospheres were obtained, and the lower layer of the nanospheres was collected and placed in a refrigerator at $4^{\circ} \mathrm{C}$ until further use.

\section{Detection of particle size and potential of $\mathrm{PFH}-\mathrm{C}_{60}$}

The size distribution and morphological characterization of PFH- $\mathrm{C}_{60}$ nanospheres were estimated by a scanning electron microscope (SEM, S-3400N; Hitachi Ltd., Tokyo, Japan). A Laser Particle Size Analyzer System (Zetasizer Nano ZS90; Malvern Instruments, Malvern, UK) was used to acquire the mean size of $\mathrm{PFH}-\mathrm{C}_{60}$ nanospheres.

\section{Double modal ultrasound imaging and $\mathrm{CT}$ of $\mathrm{PFH}-\mathrm{C}_{60}$ in vitro}

A series of the same concentrations of $\mathrm{PFH}-\mathrm{C}_{60}$ solutions and $\mathrm{C}_{60}$ solutions (using normal saline as the solvent) were placed in transparent Eppendorf tubes, and normal saline 
(NS) served as the blank control. Using the JC200 HIFU system (HIFU Technology Co.Ltd., Chongqing, People's Republic of China), we adjusted the focus and placed the Eppendorf tubes at the focal position of the HIFU probe. Different levels of acoustic power (200 and $400 \mathrm{~W}$ ) were applied to one pulse of irradiation for 3, 6, or 9 seconds. Ultrasound images, both before and after HIFU irradiation were acquired. A series of different concentrations of PFH$\mathrm{C}_{60}$ solutions and $\mathrm{a}_{60}$ solution (using NS as the solvent) were placed in transparent Eppendorf tubes, and NS served as the blank control. The echo intensity of the region of interest was determined by using US imaging analysis software (Chongqing Medical University, Chongqing, People's Republic of China). ${ }^{24}$ A GE16 slice CT scanner (LightSpeed, GE Medical System, Waukesha, WI, USA) was used to obtain images. The Eppendorf tubes were arranged in order and fixed in a holder, and the scanning parameters were adjusted to the position of the layer of interest to collect CT images. Six experimental groups were analyzed: $\mathrm{C}_{60}(4.0$ $\mathrm{mg} / \mathrm{mL}$ ) solution; pure $\mathrm{PFH}$; and $\mathrm{PFH}-\mathrm{C}_{60}$ groups (with the following $\mathrm{C}_{60}$ concentrations: 1.0, 2.0,3.0, and $4.0 \mathrm{mg} / \mathrm{mL}$ ).

\section{Qualitative evaluation of the sonodynamic effects produced by $\mathrm{PFH}-\mathrm{C}_{60}$}

Different concentrations of PFH- $\mathrm{C}_{60}$ solution (with $\mathrm{C}_{60}$ concentrations of 4.0 and $8.0 \mathrm{mg} / \mathrm{mL}$ ) and a solution of $\mathrm{C}_{60}$ (with a concentration of $8.0 \mathrm{mg} / \mathrm{mL}$ ) were placed in transparent Eppendorf tubes, each of which contained phenol solution. An unirradiated solution of $\mathrm{C}_{60}$ served as the blank control. Using the JC200 HIFU system, we adjusted the focus and placed the Eppendorf tubes at the focal position of the HIFU probe. Different levels of acoustic power (100, 200, and $300 \mathrm{~W}$ ) were applied to one pulse of irradiation for 3,6 , and 9 seconds. Images of the Eppendorf tubes were acquired both before and after HIFU irradiation.

\section{In vitro HIFU synergistic ablation efficiency}

Fresh dissected bovine livers (commercially purchased from the Chongqing Jiangbei cattle and sheep Muslim Market, Chongqing, People's Republic of China) were placed in $0.9 \% \mathrm{NS}$ at $37^{\circ} \mathrm{C}$ for 30 minutes to keep the samples warm and remove air bubbles. Samples of the experimental bovine livers $(12 \times 8 \times 6 \mathrm{~cm})$ were placed in acoustically transparent methyl methacrylate containers. The entire liver bodies were covered in degassed water, and $1 \mathrm{~mL}$ of PFH- $\mathrm{C}_{60}$ (with a $\mathrm{C}_{60}$ concentration of $8.0 \mathrm{mg} / \mathrm{mL}$ ) was injected directly into the degassed bovine livers. Using the JC200 focused ultrasound tumor therapy system, the injection sites were monitored in real time by HIFU ultrasound imaging, and the tissues were subjected to HIFU irradiation immediately after injection. The control livers were injected in the same manner with either NS or $\mathrm{C}_{60}$ and subjected to similar irradiation conditions ( $200 \mathrm{~W}$ for 9 seconds). After irradiation, changes in the video intensity of sonogram were evaluated, and the zones with altered intensities were manually traced by an experienced technician. The instrument automatically calculated the sizes of areas with gray scale changes, and the corresponding values of those gray scale changes. The conditions associated with gray scale changes were compared both before and after irradiation in each group. The bovine livers were then removed and sectioned until the level containing the maximum amount of damage was reached. The maximum dimension (length) of damage was determined from the z-axis (L), and the width was measured along the vertical $\mathrm{x}$-axis (W). Continuous lesions were produced in the same plane $(\mathrm{x}, \mathrm{y})$ by moving the HIFU generator. The ablation volumes $\left(\mathrm{V}\left[\mathrm{mm}^{3}\right]\right)$ were calculated using the following formula: ${ }^{8,25}$

$$
\mathrm{V}=\pi \times \mathrm{L} \times \mathrm{W}^{2} / 6 .
$$

\section{Ultrastructural detection of ablation zone via transmission electron microscopy (TEM)}

Bovine tissue samples of the NS group, $\mathrm{C}_{60}$ control group, and $\mathrm{PFH}-\mathrm{C}_{60}$ groups were treated with irradiation, and bovine liver tissues $\sim 1 \mathrm{~mm}^{3}$ in size (4-5 sections from each group) were quickly dissected, fixed in $2.5 \%$ glutaraldehyde, re-fixed in $2 \%$ osmic acid, dehydrated in serial alcohol gradients, and embedded to generate sections for electron microscopy. After uranyl acetate and lead citrate double staining, the samples were observed under a HITACHI-600 TEM (Hitachi).

\section{Data analysis and statistical methods}

We used SPSS17.0 statistical software program (SPSS Inc., Chicago, IL, USA) for statistical analysis of the data. Measurement data were expressed as mean $\pm \mathrm{SD}$. Comparisons among multiple groups of means were made using single factor ANOVA, and a $P$-value (error probability) $<0.05$ was considered statistically significant.

\section{Results}

A schematic diagram of the synthesis of $\mathrm{PFH}_{-} \mathrm{C}_{60}$ and its mechanism of action in HIFU applications is shown in Scheme 1. First, the fullerenes $\left(\mathrm{C}_{60}\right)$ were prepared and 


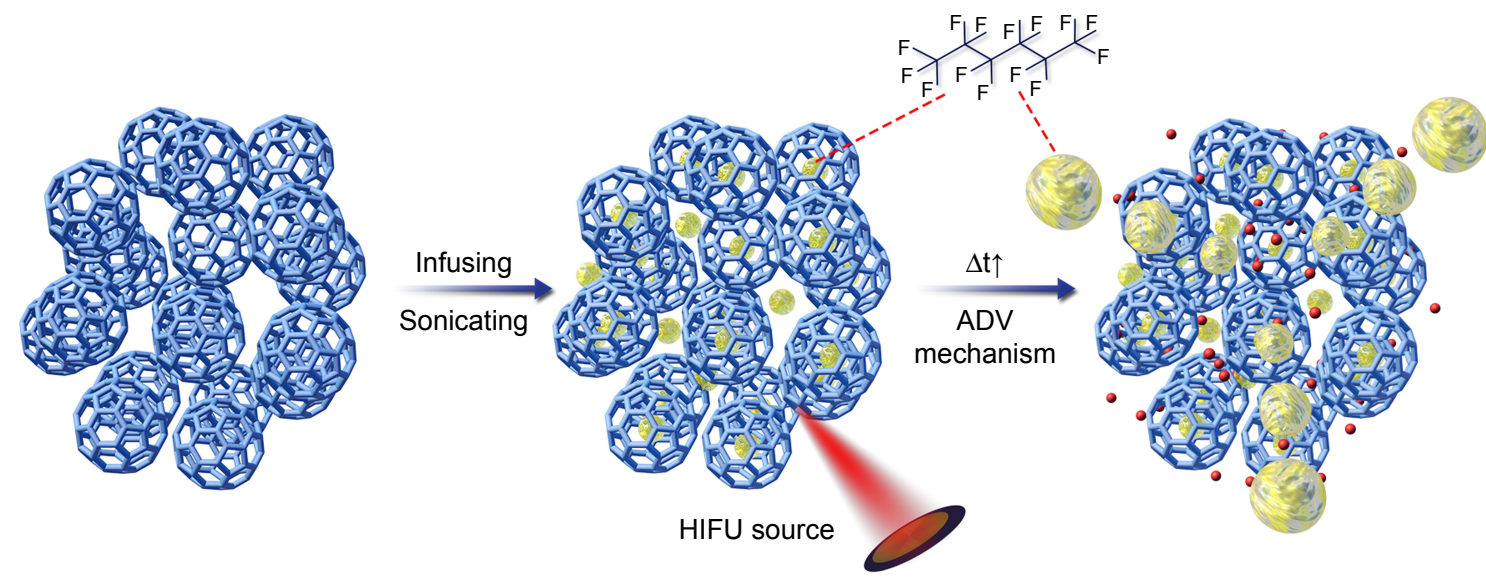

$\mathrm{C}_{60} \quad \mathrm{PFH} \quad$ Microbubble $\cdot \mathrm{ROS}$

Scheme I Schematic illustration of the formulation process for PFH- $\mathrm{C}_{60}$ nanospheres and HIFU ablation principles.

Abbreviations: $\mathrm{C}_{60}$, fullerene; $\mathrm{PFH}$, Perfluorohexane; ROS, reactive oxygen species; $A D V$, acoustic droplet vaporization; $\Delta T$, temperature variation.

temperature sensitive PFH was then carried into and between $\mathrm{C}_{60}$ shells by an ultrasonic emulsion process, and combined by van der Waals forces to form PFH- $\mathrm{C}_{60}$ nanospheres. After exposure to HIFU under previously specified conditions, the liquid PFH was vaporized into a large number of small bubbles, which accumulated and swelled into larger bubbles after accumulating in the targeted tissues. This phenomenon was expected to trigger a series of multiple effects, such as cavitation, mechanical oscillation, free-radical release, and cell membrane opening, thereby synergistically enhancing HIFU ablation. ${ }^{8}$

\section{Physical characteristics of the PFH-C 60 nanospheres}

After being dissolved in NS, the $\mathrm{PFH}_{-} \mathrm{C}_{60}$ solution appeared as a suspension of gray particles (Figure 4A) without aggregation and with obvious stratification. As shown in Figure 1A and $\mathrm{B}$, via SEM observation, the periphery of the $\mathrm{PFH}-\mathrm{C}_{60}$ nanospheres had a regular polygonal shape, and the spheres exhibited good dispersibility and a smooth surface, without an obvious aggregation or adhesion. Using the Malvern laser particle size analyzer, we determined the average diameter of the PFH-C ${ }_{60}$ nanospheres $(\varnothing)$ to be $278.3 \pm 51.0 \mathrm{~nm}$, with a focused distribution of particle sizes as shown in Figure 1C.

\section{Double modal ultrasound and CT imaging effects of $\mathrm{PFH}-\mathrm{C}_{60}$ in vitro}

The ultrasound results of $\mathrm{PFH}-\mathrm{C}_{60}$ in vitro are shown in Figure 2. Before HIFU irradiation, the $\mathrm{C}_{60}$ group, $\mathrm{PFH}_{-} \mathrm{C}_{60}$ groups, and the NS group were all hypoechoic in ultrasound images. After HIFU irradiation, the echoes were all enhanced (Figure $2 \mathrm{~A}-\mathrm{C}$ ), and the $\mathrm{PFH}^{-\mathrm{C}_{60}}$ groups showed more significant enhancement than the $\mathrm{C}_{60}$ and NS groups. Figure 2D shows the gray value of each group after HIFU irradiation, the $\mathrm{PFH}-\mathrm{C}_{60}$ group showed the largest gray value. Figure $3 \mathrm{~A}$ shows the $\mathrm{CT}$ images of $\mathrm{PFH}_{-} \mathrm{C}_{60}$ in vitro. In comparison with the $\mathrm{C}_{60}$ group, the $\mathrm{PFH}-\mathrm{C}_{60}$ group exhibited $>20$-fold increase in $C T$ value. In addition, the $C T$ value increased with increasing concentrations of $\mathrm{C}_{60}$. As shown in Figure 3B, when the $\mathrm{C}_{60}$ concentration was $4.0 \mathrm{mg} / \mathrm{L}$, the $\mathrm{CT}$ value stabilized, indicating that $\mathrm{PFH}$ packing had reached saturation. The $\mathrm{CT}$ values of $\mathrm{PFH}-\mathrm{C}_{60}$ were all above 400 and showed very good effects of $\mathrm{CT}$ enhancement.

\section{Qualitative detection of the sonodynamic effects produced by $\mathrm{PFH}-\mathrm{C}_{60}$}

Before HIFU irradiation, the solutions in the Eppendorf tubes of all groups were gray (Figure 4A). After HIFU irradiation, the color of all three groups showed notable changes. However, the conditions that led to the color change in each group and the degree of color change were not the same. In the two groups with $\mathrm{PFH}-\mathrm{C}_{60}$ solutions, the conditions that led to color change consisted of $200 \mathrm{~W}$ for 6 and 9 seconds and $300 \mathrm{~W}$ for 6 and 9 seconds, whereas the conditions of the $\mathrm{C}_{60}$ solution group consisted of $300 \mathrm{~W}$ for 9 seconds. The group with a higher concentration of $\mathrm{PFH}^{-\mathrm{C}_{60}}$ showed more pronounced effects than the group with a lower concentration. The PFH-C ${ }_{60}\left(\mathrm{C}_{60} 8.0 \mathrm{mg} / \mathrm{mL}\right)$ group was irradiated for $200 \mathrm{~W} / 9$ 

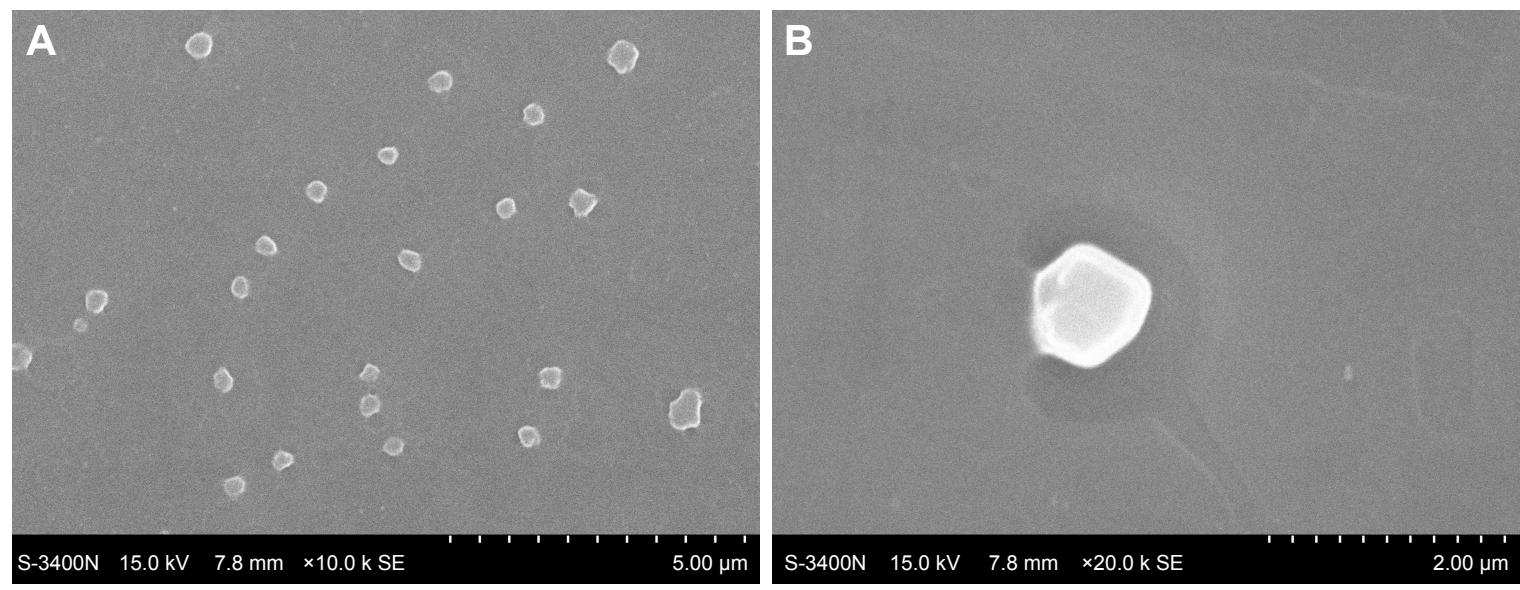

\begin{tabular}{|l|lllll|}
\hline \multicolumn{5}{|l}{} & \multicolumn{2}{l}{ Diam $(\mathbf{n m})$} & \% intensity & Width (nm) \\
\cline { 2 - 6 } & Z-average (d.nm): 278.3 & Peak 1: 255.9 & 100.0 & 51.02 \\
Pdl & $: 0.213$ & Peak 2: 0.000 & 0.0 & 0.000 \\
Intercept & $: 0.959$ & Peak 3: 0.000 & 0.0 & 0.000 \\
Result quality & $:$ good & & & & \\
\hline
\end{tabular}

Size distribution by intensity

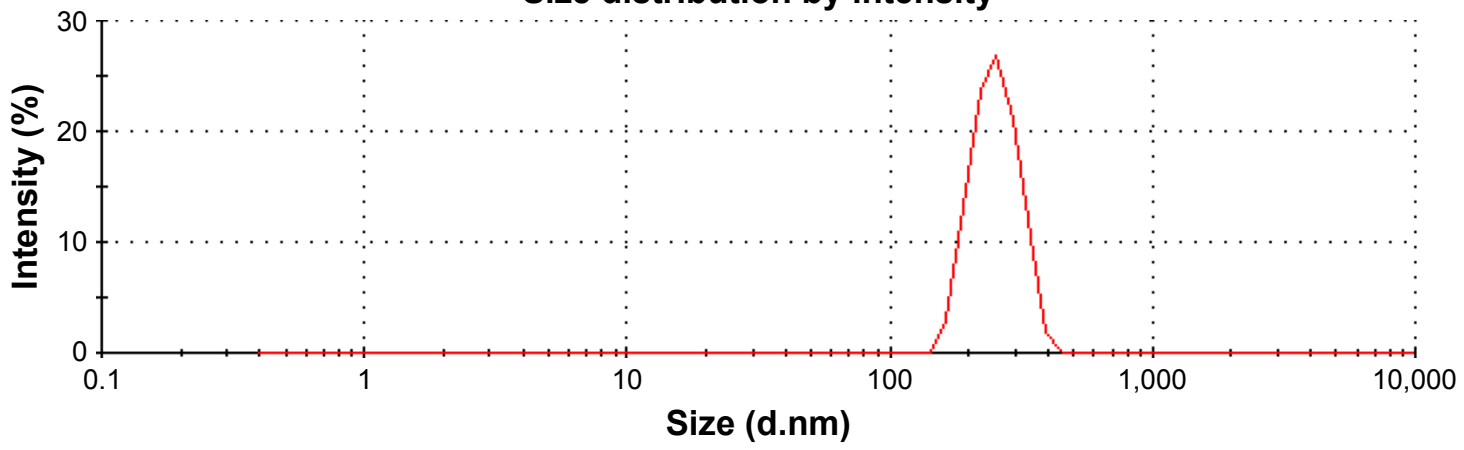

Figure I (A, B) SEM images of prepared PFH-C 60 composite nanospheres at different magnifications; (C) hydrolyzed particle size distributions of PFH-C 60 composite nanospheres based on DLS measurements.

Abbreviations: SEM, scanning electron microscope; $\mathrm{C}_{60}$, fullerene; $\mathrm{PFH}$, perfluorohexane; $\mathrm{DLS}$, dynamic light scattering.

seconds, and the solution turned dark brown (Figure 4B). The PFH- $\mathrm{C}_{60}\left(\mathrm{C}_{60} 4.0 \mathrm{mg} / \mathrm{mL}\right)$ group was irradiated for $200 \mathrm{~W} / 9$ seconds, and the solution turned brown (Figure 4C). Whereas the color of the $\mathrm{C}_{60}(8.0 \mathrm{mg} / \mathrm{mL})$ group under higher intensity irradiation parameters of $300 \mathrm{~W} / 9$ seconds showed only a slight change to light brown (Figure 4D).

\section{In vitro HIFU enhancement effects}

After HIFU ablation, the area affected by coagulation necrosis was grayish-white and showed clear boundaries with the surrounding tissue. Figure 5A depicts the sonograms of each group immediately after HIFU ablation, under similar conditions of duration, probe frequency, and radiation acoustic power and time. Figure 5B shows a diverse scope and extent of bovine liver ablation and the gross appearance of different groups after HIFU irradiation. Figure 5C-E shows the volume of coagulation necrosis, gray areas, and gray value of each group after HIFU irradiation. The results showed that the $\mathrm{PFH}-\mathrm{C}_{60}$ group was the most effective group.

\section{TEM detection of ultrastructures}

Figure 6A shows that the NS group presented cell membranes and nuclearmembranes were intact, the mitochondria and endoplasmic reticulum were slightly distended. However, in the other two groups, especially in the $\mathrm{PFH}-\mathrm{C}_{60}$ group, the structure of cells were not clear, and most cell membranes and nuclear membranes were interrupted or undefined, although some were lysed, which further demonstrates the synergistic effect. Moreover, in the group receiving the injection of $\mathrm{C}_{60}$ and $\mathrm{PFH}-\mathrm{C}_{60}$ solution, $\mathrm{C}_{60}$ nanoparticles were seen regularly depositing in the cytoplasm around the nuclear membranes in residual liver cells (Figure 6B and C), indicating that the 

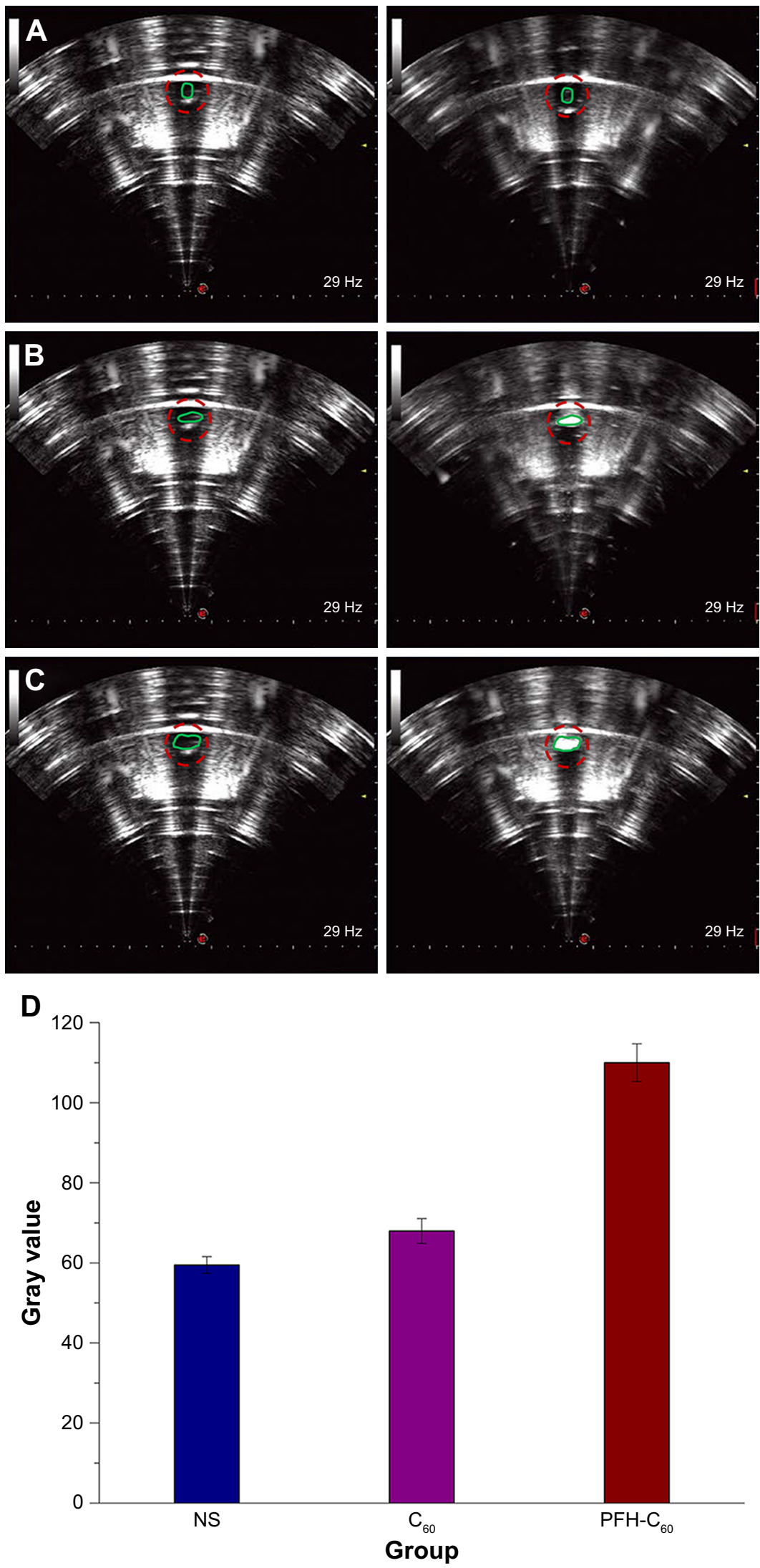

Figure 2 Ex vitro evaluations of the efficiencies of the same irradiation powers and time durations for ultrasound imaging under different groups [NS ( $\mathbf{A})$; $\mathrm{C}_{60}$ solutions $(\mathbf{B})$; $\mathrm{PFH}-\mathrm{C}_{60}$ solutions (C); left images: before irradiation, right images: after irradiation]. (D) Corresponding gray values of the interest region (each column is the average of three data points).

Abbreviations: NS, normal saline; $\mathrm{C}_{60}$, fullerene; $\mathrm{PFH}$, perfluorohexane. 
A

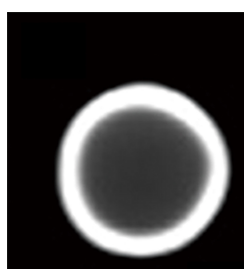

a

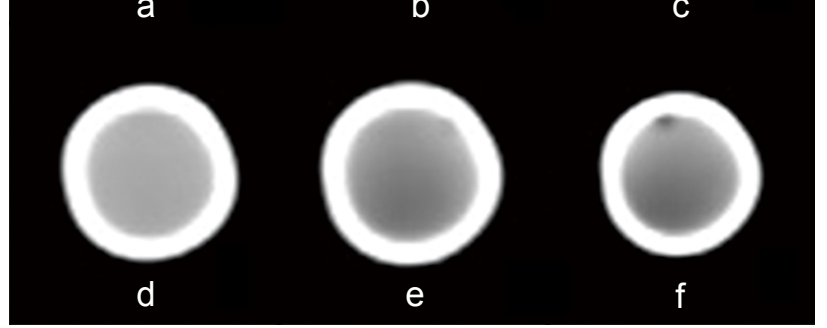

B

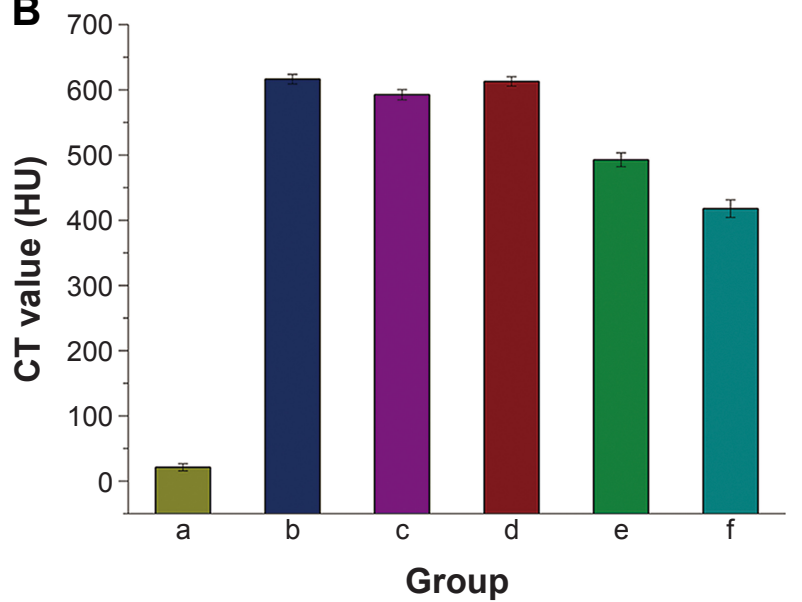

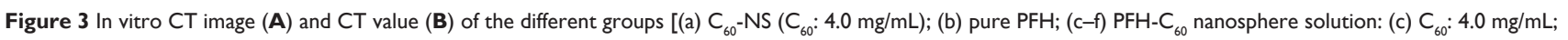
(d) $\mathrm{C}_{60}: 3.0 \mathrm{mg} / \mathrm{mL}$; (e) $\mathrm{C}_{60}: 2.0 \mathrm{mg} / \mathrm{mL}$; (f) $\mathrm{C}_{60}: 1.0 \mathrm{mg} / \mathrm{mL}$ ].

Abbreviations: NS, normal saline; $\mathrm{C}_{60}$, fullerene; $\mathrm{PFH}$, perfluorohexane; $\mathrm{CT}$, computed tomography.

composite nanosphere could enter the cell and target tissue to enhance the HIFU therapeutic efficiency.

\section{Discussion}

The multifunctional PFH- $\mathrm{C}_{60}$ nanosphere developed in our study exhibited favorable characteristics for US/CT imaging and synergistic HIFU therapy. The average particle size of PFH- $\mathrm{C}_{60}$ is about $287 \mathrm{~nm}$, which is in line with the particle size range of nanoscale materials. In scanning electron microscopy, $\mathrm{PFH}-\mathrm{C}_{60}$ nanospheres exhibit structural features that are similar to football-like shapes. In ultrasound imaging studies, when sound beams enter the vicinity of interfaces with differences in acoustic impedance, the sound beams will be reflected at the interfaces. After HIFU irradiation, the PFH-C ${ }_{60}$ solution showed a more significantly enhanced

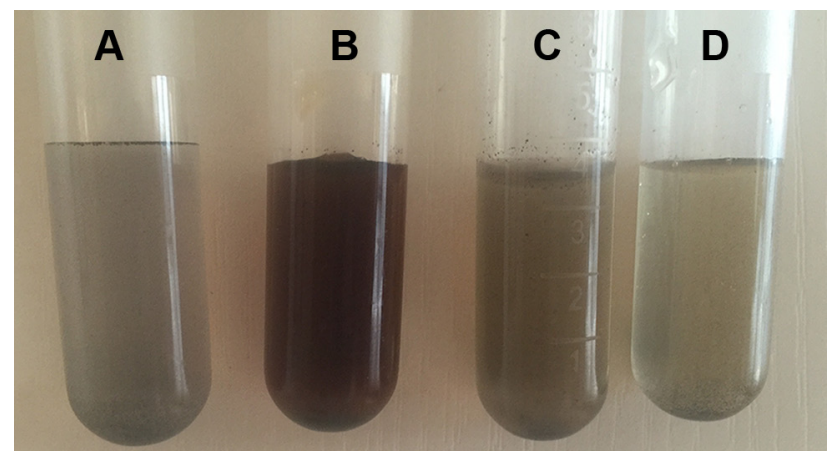

Figure 4 (A) Gray color of unirradiated $C_{60}$ solution; (B) dark brown color of $\mathrm{PFH}_{-} \mathrm{C}_{60}\left(\mathrm{C}_{60} 8.0 \mathrm{mg} / \mathrm{mL}\right)$ solution after irradiation; (C) brown color of $\mathrm{PFH}-\mathrm{C}_{60}$ $\left(C_{60} 4.0 \mathrm{mg} / \mathrm{mL}\right)$ solution after irradiation; (D) light brown color of $C_{60}(8.0 \mathrm{mg} / \mathrm{mL})$ solution after irradiation (B, C: HIFU irradiation: 200 W/9 seconds; D: HIFU irradiation: $300 \mathrm{~W} / 9$ seconds).

Abbreviations: $\mathrm{C}_{60}$, fullerene; $\mathrm{PFH}$, perfluorohexane; HIFU, high-intensity focused ultrasound. echo signal than those of the other groups, may be closely associated with the fact that the HIFU irradiation met or exceeded the threshold of PFH phase changes and caused the PFH- $\mathrm{C}_{60}$ nanospheres to be transformed into bubbles. ${ }^{26}$ Therefore, the principle of ultrasound imaging of the PFH$\mathrm{C}_{60}$ solution is based mainly on the backscattering of bubbles generated by PFH phase transition, whereas the principle of ultrasound imaging of the $\mathrm{C}_{60}$ solution is based on aggregate imaging. From the perspective of the imaging principles, the effects of aggregate imaging are far less than those of bubble backscattering. ${ }^{27}$ In the $\mathrm{CT}$ imaging studies, the PFH-C ${ }_{60}$ group showed better results than the other groups. When the concentration of PFH was kept constant, the $\mathrm{CT}$ value increased with increasing of $\mathrm{C}_{60}$ concentration. When the $\mathrm{C}_{60}$ concentrations were 3.0 and $4.0 \mathrm{mg} / \mathrm{mL}$, respectively, the CT value showed no change significant change. This may have been due to saturation of the $\mathrm{C}_{60}$ carrying $\mathrm{PFH}$. Regarding the qualitative detection of sonodynamic effects, the color change in the $\mathrm{PFH}-\mathrm{C}_{60}$ solution groups was attributed to the production of ROS and free radicals, which led to the rapid oxidation of phenol benzene to produce quinine. For the in vitro $\mathrm{PFH}-\mathrm{C}_{60}$ bimodal ultrasound/CT imaging and qualitative detection of the sonodynamic effects, multiple groups were subjected to different concentrations of $\mathrm{C}_{60}$ and different HIFU irradiation conditions; however, the results showed notable images under only under one set of conditions: HIFU irradiation $200 \mathrm{~W} / 9$ seconds and $\mathrm{C}_{60} 8.0 \mathrm{mg} / \mathrm{mL}$. The primary reason was that this part of the experiment, in addition to the imaging enhancement effect, can also achieve selection of a set of optimization parameters in the subsequent in vitro bovine liver HIFU synergistic experiment; then, the setting 

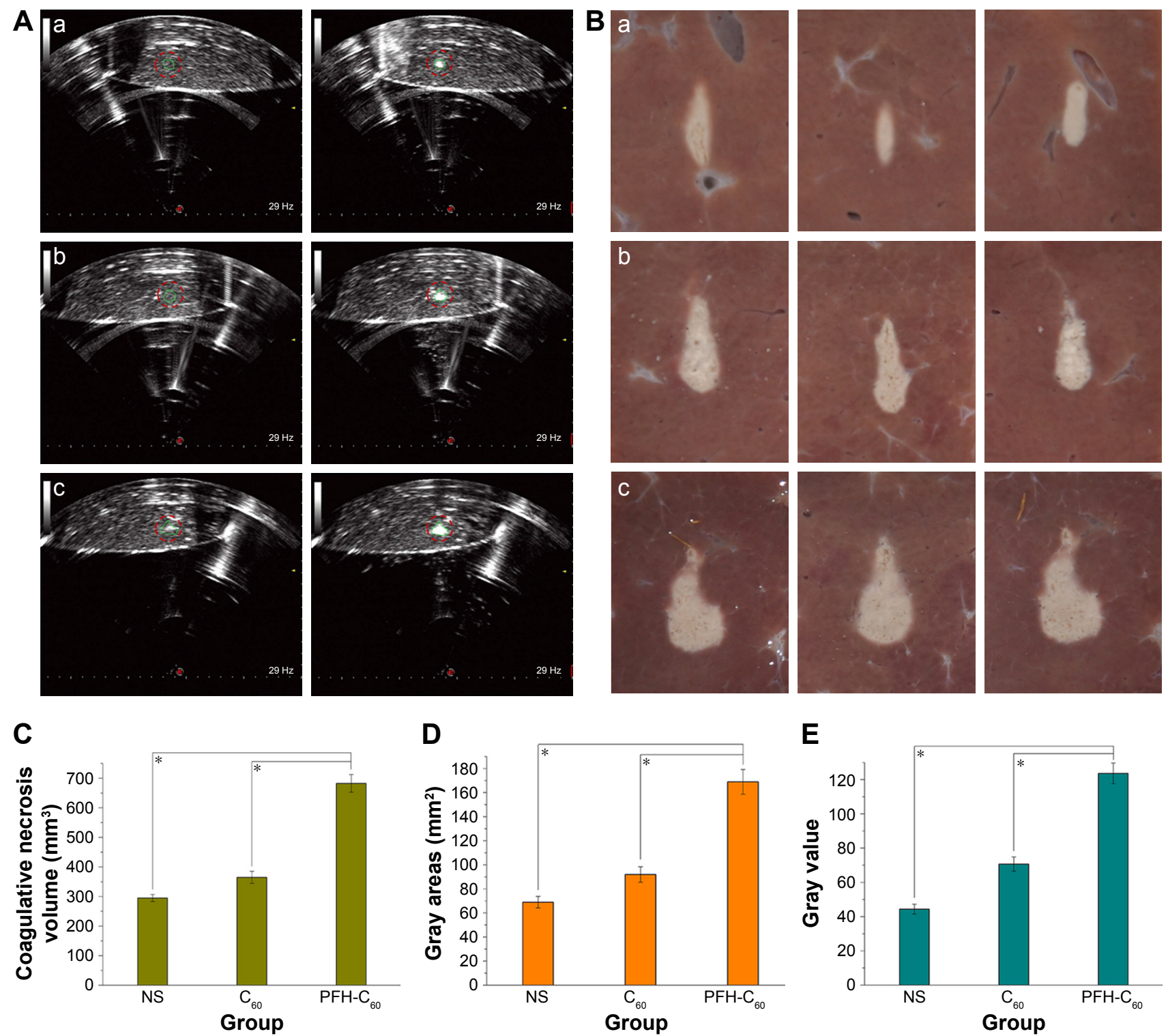

Figure 5 (A) Ex vivo evaluation of the efficiency of ultrasound imaging and HIFU therapy under the same irradiation power and duration (200 W for 9 seconds) for these three groups after intra-tissue injection of solutions and HIFU exposure of bovine livers (NS (a); $\mathrm{C}_{60}$ (b); PFH-C ${ }_{60}$ (c); left images: before irradiation; right images: after irradiation). (B) Digital photos of ablated bovine livers (NS (a); $\mathrm{C}_{60}$ (b); $\mathrm{PFH}_{-\mathrm{C}_{60}}$ (c)). (C-E) Corresponding necrotic volume, gray areas, and gray value (each column is the average of three data points).

Note: *Significant differences between comparing $\mathrm{PFH}-\mathrm{C}_{60}$ and $\mathrm{C}_{60}$, or the NS control at $\mathrm{P} \leq 0.0 \mathrm{I}$, respectively.

Abbreviations: NS, normal saline; $\mathrm{C}_{60}$, fullerene; $\mathrm{PFH}$, perfluorohexane; HIFU, high-intensity focused ultrasound.

of many sub-experiments under different concentrations of $\mathrm{C}_{60}$ and HIFU irradiation parameters inevitably resulted in several images from the applied ultrasound. Attempting to attach all the obtained images would occupy a large amount of space; however, the most critical is to select the optimal parameters from these results for the next experiment. Therefore, the results did not show all the images, but just only showed the ultrasound images under the optimized parameters (200 W/9 seconds), which was the same parameters as the in vitro bovine liver HIFU synergistic experiment.

Regarding the vitro HIFU enhancement effects, the parameters of $200 \mathrm{~W}$ and 9 seconds were mainly chosen because the HIFU thermal effects at this energy level may reach the PFH boiling point and lead to sonodynamic effects. This choice was also based on the optimization data obtained in the experiment of in vitro $\mathrm{PFH}-\mathrm{C}_{60}$ bimodal ultrasound/ CT imaging and qualitative detection of the sonodynamic effects. The in vitro bovine liver irradiation experiment compared the PFH- $\mathrm{C}_{60}$ experimental group to the NS and $\mathrm{C}_{60}$ groups and showed that when subjected to the same irradiation duration and acoustic energy, the $\mathrm{PFH}-\mathrm{C}_{60}$ experimental group was the first group to form significant triangular areas of coagulation necrosis that were visible to the naked eye. Under an electron microscope, the irradi- 

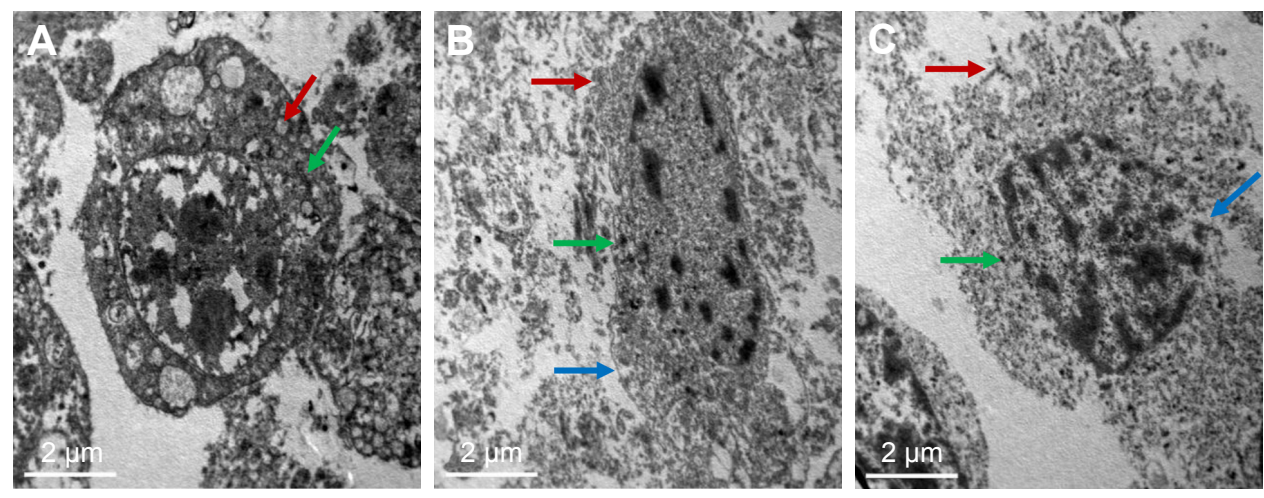

Figure 6 (A) HIFU + NS group: the mitochondria (red arrow) and endoplasmic reticulum (green arrow) were slightly distended; (B) HIFU + C ${ }_{60}$ groups: cell membranes (red arrow) were lightly interrupted, a few deposits of $\mathrm{C}_{60}$ (green arrow) were observed in the cytoplasm, and a clear nuclear membrane (blue arrow) was still observed; (C) HIFU + PFH-C 60 group: most cell membranes (red arrow) and nuclear membranes (blue arrow) were almost interrupted or undefined, several deposits of $\mathrm{C}_{60}$ (green arrow) were observed in the cytoplasm around the nuclear membranes.

Abbreviations: NS, normal saline; $\mathrm{C}_{60}$, fullerene; $\mathrm{PFH}$, perfluorohexane; HIFU, high-intensity focused ultrasound.

ated areas of the $\mathrm{PFH}-\mathrm{C}_{60}$ experimental group showed more significant nuclear fragmentation and karyolysis than the other groups. This confirmed that $\mathrm{PFH}-\mathrm{C}_{60}$ can exert significant HIFU enhancement effects, achieved through multiple mechanisms, such as cavitation and sonochemical reactions. In sonodynamic therapy, the activation of sonosensitive agents by ultrasonic acoustic cavitation can be attributed to the generation of ROS. ${ }^{28-30}$ Ultrasound radiation induces cavitation around the surface of tumor cells, which can produce sonochemical reactions, the rupture of living cells, white noise, and emission of light or sonoluminescence. When a sonosensitive agent attached to the surface of a tumor cell is exposed to sonoluminescence, the sensitizer is activated from its ground state to an excited state. When the activated sonosensitive agent returns to its ground state, the released energy can generate free radicals and ROS, which directly mediate cytotoxicity. ${ }^{31}$ Thus, $\mathrm{PFH}-\mathrm{C}_{60}$ can be used as a potential sonosensitizer for the treatment of tumors in combination with ultrasound. Upon HIFU irradiation of the

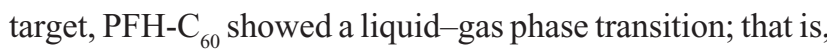
ADV caused the nanospheres to be transformed into microbubbles. The vibration of the microbubbles enhanced thermal energy deposition, thus improving the efficiency of HIFU, reducing the inertial cavitation threshold, and enhancing focused ultrasound cavitation. These processes can achieve HIFU enhancement by changing the acoustic environment of tissues and thereby enhancing energy deposition at target areas. Ultrasonic cavitation is an effective measure by which low-density elastic wave energy can be concentrated into a higher density. Subsequently, the energy becomes focused into a very small volume and generates an intense effect with the bursting and vibration of bubbles; the energy produced can have a disruptive effect in cells and tissue. ${ }^{32,33}$
The administration of $\mathrm{PFH}-\mathrm{C}_{60}$ induced the most significant signal enhancement, which implies that $\mathrm{PFH}-\mathrm{C}_{60}$ could produce the highest synergistic effect in in vitro HIFU enhancement studies. The PFH- $\mathrm{C}_{60}$ complex underwent reactions with free radical and had a strong acoustic dynamic effect in target areas. In addition, previous studies have shown that $\mathrm{C}_{60}$ and its derivatives have the potential for a wide range of applications in the pharmaceutical industry and can inhibit or kill cancer cells or abnormal cells in vitro under specific conditions. ${ }^{34-37}$ A novel type of phase changeable nanosphere was developed as a dual-mode bioimaging contrast agent for high-efficiency ultrasound and CT imaging, and synergist for HIFU, through the in situ introduction of a PFH droplet into fullerene $\left(\mathrm{C}_{60}\right)$ nanospheres via a vacuum emulsion centrifugation process. The $\mathrm{PFH}-\mathrm{C}_{60}$ nanospheres exhibited excellent in vitro contrast-enhanced imaging capabilities for ultrasound and CT dual-modality bioimaging. Notably, as demonstrated by the results of the present bovine liver ablation study, the PFH- $\mathrm{C}_{60}$ nanospheres can be applied as a synergistic agent in non-invasive HIFU therapy to enhance its therapeutic efficiency.

\section{Conclusion}

We developed perfluorohexane-encapsulated fullerene nanospheres as dual-mode bioimaging contrast agents via a vacuum ultrasonic emulsification and centrifugation method, for effective ultrasound and CT imaging, and synergists for HIFU surgery introduced by in-situ. The present results confirm the excellent contrast-enhanced imaging capabilities of the PFH- $\mathrm{C}_{60}$ nanospheres for ultrasound and $\mathrm{CT}$ bimodal bioimaging. Notably, the PFH- $\mathrm{C}_{60}$ nanospheres have been recognized as potentiators that enhance the therapeutic efficiency of HIFU in the non-invasive ablation procedures. 
Thus, the application of $\mathrm{PFH}-\mathrm{C}_{60}$ composite nanospheres is a potential technique for bimodal bioimaging and enhanced imaging-guided non-invasive HIFU therapy.

\section{Acknowledgment}

This research was financially supported by the National Natural Science Foundation of People's Republic of China (Grant No 81630047, 81471713, 81601513, cstc2018jcyjAX0747).

\section{Disclosure}

The authors report no conflicts of interest in this work.

\section{References}

1. Gelet A, Chapelon JY, Poissonnier L, et al. Local recurrence of prostate cancer after external beam radiotherapy: early experience of salvage therapy using high-intensity focused ultrasonography. Urology. 2004;63(4):625-629.

2. Chan AH, Fujimoto VY, Moore DE, Held RT, Paun M, Vaezy S. In vivo feasibility of image-guided transvaginal focused ultrasound therapy for the treatment of intracavitary fibroids. Fertil Steril. 2004;82(3):723-730.

3. Esnault O, Franc B, Ménégaux F, et al. High-intensity focused ultrasound ablation of thyroid nodules: first human feasibility study. Thyroid. 2011;21(9):965-973.

4. Illing RO, Kennedy JE, Wu F, et al. The safety and feasibility of extracorporeal high-intensity focused ultrasound (HIFU) for the treatment of liver and kidney tumours in a Western population. Br J Cancer. 2005; 93(8):890-895.

5. Lynn JG, Zwemer RL, Chick AJ, Miller AE. A new method for the generation and use of focused ultrasound in experimental biology. J Gen Physiol. 1942;26(2):179-193.

6. Orsi F, Arnone P, Chen W, Zhang L. High intensity focused ultrasound ablation: a new therapeutic option for solid tumors. J Cancer Res Ther. 2010;6(4):414-420.

7. Rowland IJ, Rivens I, Chen L, et al. MRI study of hepatic tumours following high intensity focused ultrasound surgery. Br J Radiol. 1997; 70:144-153.

8. Wang X, Chen H, Chen Y, et al. Perfluorohexane-encapsulated mesoporous silica nanocapsules as enhancement agents for highly efficient high intensity focused ultrasound (HIFU). Adv Mater. 2012;24(6): 785-791.

9. Kennedy JE. High-intensity focused ultrasound in the treatment of solid tumours. Nat Rev Cancer. 2005;5(4):321-327.

10. ter Haar G. Ultrasound focal beam surgery. Ultrasound Med Biol. 1995; 21(9):1089-1100.

11. Sun Y, Zheng Y, Ran H, et al. Superparamagnetic PLGA-iron oxide microcapsules for dual-modality US/MR imaging and high intensity focused US breast cancer ablation. Biomaterials. 2012;33(24): 5854-5864.

12. Li YY, Sha WH, Zhou YJ, Nie YQ. Short and long term efficacy of high intensity focused ultrasound therapy for advanced hepatocellular carcinoma. J Gastroenterol Hepatol. 2007;22(12):2148-2154.

13. Li JJ, Xu GL, Gu MF, et al. Complications of high intensity focused ultrasound in patients with recurrent and metastatic abdominal tumors. World J Gastroenterol. 2007;13(19):2747-2751.

14. Wu F, Wang ZB, Chen WZ, et al. Extracorporeal high intensity focused ultrasound ablation in the treatment of patients with large hepatocellular carcinoma. Ann Surg Oncol. 2004;11(12):1061-1069.

15. Tran BC, Jongbum S, Hall TL, Fowlkes JB, Cain CA. Microbubbleenhanced cavitation for noninvasive ultrasound surgery. IEEE Trans Ultrason, Ferroelect Freq Control. 2003;50(10):1296-1304.

16. Yu T, Xiong S, Mason TJ, Wang Z. The use of a micro-bubble agent to enhance rabbit liver destruction using high intensity focused ultrasound. Ultrason Sonochem. 2006;13(2):143-149.
17. Isern J, Pessarrodona A, Rodriguez J, et al. Using microbubble sonographic contrast agent to enhance the effect of high intensity focused ultrasound for the treatment of uterine fibroids. Ultrason Sonochem. 2015; 27:688-693.

18. Zderic V, Foley J, Luo W, Vaezy S. Prevention of post-focal thermal damage by formation of bubbles at the focus during high intensity focused ultrasound therapy. Med Phys. 2008;35(10):4292-4299.

19. Chen Y, Chen H, Sun Y, et al. Multifunctional mesoporous composite nanocapsules for highly efficient MRI-guided high-intensity focused ultrasound cancer surgery. Angew Chem Int Ed Engl. 2011;50(52): 12505-12509.

20. Díaz-López R, Tsapis N, Fattal E. Liquid perfluorocarbons as contrast agents for ultrasonography and ${ }^{(19) \mathrm{F}}$-MRI. Pharm Res. 2010;27(1):1-16.

21. Rapoport NY, Efros AL, Christensen DA, Kennedy AM, Nam K-H. Microbubble generation in phase-shift nanoemulsions used as anticancer drug carriers. Bubble Sci Eng Technol. 2009;1(1-2):31-39.

22. Partha R, Conyers JL. Biomedical applications of functionalized fullerene-based nanomaterials. Int J Nanomedicine. 2009;4:261-275.

23. Mroz P, Tegos GP, Gali H, Wharton T, Sarna T, Hamblin MR. Photodynamic therapy with fullerenes. Photochem Photobiol Sci. 2007;6(11): $1139-1149$.

24. Liu J, Shang T, Wang F, et al. Low-intensity focused ultrasound (LIFU)-induced acoustic droplet vaporization in phase-transition perfluoropentane nanodroplets modified by folate for ultrasound molecular imaging. Int J Nanomedicine. 2017;12:911-923.

25. ter Haar G, Rivens I, Chen L, Riddler S. High intensity focused ultrasound for the treatment of rat tumours. Phys Med Biol. 1991;36(11): $1495-1501$.

26. Kripfgans OD, Fowlkes JB, Miller DL, Eldevik OP, Carson PL. Acoustic droplet vaporization for therapeutic and diagnostic applications. Ultrasound Med Biol. 2000;26(7):1177-1189.

27. Marsh JN, Partlow KC, Abendschein DR, Scott MJ, Lanza GM, Wickline SA. Molecular imaging with targeted perfluorocarbon nanoparticles: quantification of the concentration dependence of contrast enhancement for binding to sparse cellular epitopes. Ultrasound Med Biol. 2007;33(6):950-958.

28. Didenko YT, McNamara WB, Suslick KS. Molecular emission from single-bubble sonoluminescence. Nature. 2000;407(6806):877-879.

29. Rosenthal I, Sostaric JZ, Riesz P. Sonodynamic therapy - a review of the synergistic effects of drugs and ultrasound. Ultrason Sonochem. 2004;11(6):349-363.

30. Yumita N, Nishigaki R, Umemura K, Umemura S. Hematoporphyrin as a sensitizer of cell-damaging effect of ultrasound. Jpn J Cancer Res. 1989;80(3):219-222.

31. Kuroki M, Hachimine K, Abe H, et al. Sonodynamic therapy of cancer using novel sonosensitizers. Anticancer Res. 2007;27(6A):3673-3677.

32. Miller DL, Pislaru SV, Greenleaf JE. Sonoporation: mechanical DNA delivery by ultrasonic cavitation. Somat Cell Mol Genet. 2002;27(1-6): $115-134$.

33. Keshavarzi A, Vaezy S, Noble ML, et al. Treatment of uterine leiomyosarcoma in a xenograft nude mouse model using high-intensity focused ultrasound: a potential treatment modality for recurrent pelvic disease. Gynecol Oncol. 2002;86(3):344-350.

34. Diederich FO, Thilgen C. Covalent fullerene chemistry. Science. 1996; 271(5247):317-324.

35. Scrivens WA, Tour JM, Creek KE, Pirisi L. Synthesis of 14C-Labeled C60, Its Suspension in Water, and Its Uptake by Human Keratinocytes. J Am Chem Soc. 1994;116(10):4517-4518.

36. Tokuyama H, Yamago S, Nakamura E, Shiraki T, Sugiura Y. Photoinduced biochemical activity of fullerene carboxylic acid. $J$ Am Chem Soc. 1993;115(17):7918-7919.

37. Schinazi RF, Mead JR, Feorino PM. Insights into HIV chemotherapy. AIDS Res Hum Retroviruses. 1992;8(6):963-990. 
International Journal of Nanomedicine

Dovepress

\section{Publish your work in this journal}

The International Journal of Nanomedicine is an international, peerreviewed journal focusing on the application of nanotechnology in diagnostics, therapeutics, and drug delivery systems throughout the biomedical field. This journal is indexed on PubMed Central, MedLine, CAS, SciSearch ${ }^{\circledR}$, Current Contents ${ }^{\circledR} /$ Clinical Medicine,
Journal Citation Reports/Science Edition, EMBase, Scopus and the Elsevier Bibliographic databases. The manuscript management system is completely online and includes a very quick and fair peer-review system, which is all easy to use. Visit http://www.dovepress.com/ testimonials.php to read real quotes from published authors.

Submit your manuscript here: http://www.dovepress.com/international-journal-of-nanomedicine-journal 